\title{
Prevalence and heritability of psoriasis and benign migratory glossitis in one Brazilian population ${ }^{*}$
}

\author{
Maria Augusta Jorge ${ }^{1}$ \\ Jane Tomimori ${ }^{3}$ \\ Calógeras Antônio Barbosa ${ }^{5}$
}

\author{
Heron Fernando de Sousa Gonzaga ${ }^{2}$ \\ Bruna Lavinas Sayed Picciani ${ }^{4}$
}

DOI: http:/ /dx.doi.org/10.1590/abd1806-4841.20176389

\begin{abstract}
BACKGROUND: An oral condition associated to psoriasis is benign migratory glossitis. The review of the literature does not show any publication about heritability in both psoriasis and benign migratory glossitis and prevalence of psoriasis in the Brazilian population.

OвJестіvE: This research was carried out in order to determine the prevalence of psoriasis and benign migratory glossitis in the Brazilian population from a Brazilian sample, as well as the heritability in these conditions.

METHODS: Six thousand patients were studied from the records of the outpatient dermatology department. The sample had 129 patients with cutaneous psoriasis, 399 with benign migratory glossitis without psoriasis and a control group with 5,472 patients. After data collection, the statistical analysis was made using Woolf, Chi-square and Falconer tests.

RESULTS: The prevalence of psoriasis was $2.15 \%$ and the benign migratory glossitis was $7.0 \%$. The prevalence of benign migratory glossitis in the psoriasis group was high (16.3\%), and that was statistically significant. Family history in the psoriasis group was 38\% for the condition itself and 2,75\% for benign migratory glossitis and in the benign migratory glossitis group was $17.54 \%$ for the condition itself and $1.5 \%$ for psoriasis. The study of heritability was $38.8 \%$ for psoriasis and $36.6 \%$ for benign migratory glossitis, both with medium heritability.
\end{abstract}

StUdY LimitaTiOns: This study was only in the state of São Paulo.

Conclusion: This is the first publication that quantifies how much of these conditions have a genetic background and how important the environmental factors are in triggering them.

Keywords: Genetics; Glossitis, benign migratory; Psoriasis; Prevalence

\section{INTRODUCTION}

Psoriasis (PS) is a chronic cutaneous disease with genetic and immunological basis triggered by environmental factors. ${ }^{1-3}$ Clinically, the lesions present as erythematous papules and plaques, covered by white scales. The lesions are frequently symmetric and show predilection for the scalp, nails, posterior region of the elbows and anterior region of the knees. The disease can be localized or generalized, affecting almost all the skin. PS has unpredictable course, with spontaneous improvement or exacerbation of the lesions., ${ }^{3,4}$
An oral condition associated to PS is benign migratory glossitis (BMG) ${ }^{5-7}$ Also termed geographic tongue, BMG is characterised by irregular areas of loss of filiform papillae, surrounded by white margins with subtle elevation. As a characteristic, these areas vary widely in appearance, size, number, location, due to the healing of one edge and proliferation of another; they frequently disappear, recur and coalesce in variable proportions, so that the lesions appear to migrate. ${ }^{8,9}$ The increased prevalence of BMG among

\footnotetext{
Received on 19.08.2016.

Approved by the Advisory Board and accepted for publication on 25.03.2017.

* Work performed at the Discipline of Dermatology, Medical School, Universidade de Marília (Unimar) - Marília (SP), Brazil.

Financial support: None.

Conflict of interest: None.

Research Center, Centro de Ensino Superior de Dracena (CESD) - Dracena, SP, Brazil.

Discipline of Dermatology, Medical School, Universidade de Marília (Unimar) - Marília (SP), Brazil.

Department of Dermatology, Universidade Federal de São Paulo (Unifesp) - São Paulo (SP), Brazil.

Department of Pathology, Medical School, Universidade Federal Fluminense (UFF) - Niterói (RJ), Brasil.

Department of Genetics and Evolution, Faculty of Health Sciences, Universidade Federal de São Carlos (UFSCar) - São Carlos (SP), Brazil.

(C)2017 by Anais Brasileiros de Dermatologia
} 
psoriatic patients and similar microscopic characteristics, support the idea that PS and BMG are associated conditions. ${ }^{10-12}$ This association was reinforced by the determination of a genetic marker, the antigen HLA-Cw6, common for both PS and BMG, suggesting that these conditions could share the same genetic basis. ${ }^{5}$ Nevertheless, clinical expression led us to question the differences of biological and environmental factors.

Regarding the genetic determinants, the fact that HLACw6 is not the only factor, as both PS and BMG have been classified as polygenic diseases, must be considered. In PS, the involvement of major loci in chromosomes $6 \mathrm{p}, 17 \mathrm{q}, 4 \mathrm{q}, 2 \mathrm{p}, 8 \mathrm{q}$ e $20 \mathrm{p}$ was determined. ${ }^{13-15} \mathrm{In}$ BMG, the investigation was performed only in locus $6 p .^{5}$ Accumulated evidence indicates that PS is a multifactorial disorder caused by the concerted action of multiple disease genes in a single individual, triggered by environmental factors. Some of these genes control the severity of multiple diseases by regulating inflammatory processes and immunity (severity genes); whereas others are unique to PS. Various combinations of these genes can occur even within a single family, being largely responsible for many manifestations of PS. Many unaffected individuals carry one or more disease alleles, but lack other genetic and/or environmental factors necessary to develop the disease. ${ }^{16}$

BMG, disease associated to PS, is also a multifactorial disease. ${ }^{17}$ Considering that environmental factors may be important in the expression of the disease, the study of heritability might determine how much the phenotype variability of these diseases is due to the genotype or to the environment. Falconer's test could be used to answer these questions. ${ }^{18}$ To apply this test, the prevalence of the disease in the studied population must be used. The review of literature did not show any publication about heritability in both PS and BMG, nor studies of the prevalence of PS in the Brazilian population. The aim of this study was to determine the prevalence of PS and BMG in a population of the State of São Paulo, Brazil, and the heritability of these conditions.

\section{METHODS}

The study included 6.000 dermatology patients from the São Paulo Outpatient Clinic of Dermatology between 2004 and 2008. The retrospective data were collected from the patient's records at the Outpatient Clinic. All patients were submitted to an oral mucosa and skin examination by an experienced examiner in Stomatology and Dermatology using artificial light, gloves, and a tongue depressor for evaluation of oral soft tissues. The sample consisted of 129 patients with cutaneous PS and 5,871 individuals with other dermatological conditions, considered the control group (CG). The patients with cutaneous PS presented BMG simultaneously or not. The CG consisted of patients with superficial mycoses by dermatophytes (780; 14\%), dyschromia (662; 12\%), eczematous diseases $(595 ; 10.8 \%)$, inflammatory skin diseases $(585 ; 10.6 \%)$, erythemato-squamous diseases, psoriasis excluded $(515 ; 9 \%)$, pityriasis versicolor $(325 ; 6 \%)$, benign skin tumors (300; 5\%), alopecias $(270 ; 4.9 \%)$, scabies $(247 ; 4 \%)$, pruritic papular eruptions $(210 ; 3.8 \%)$, cutaneous viral diseases $(155 ; 2.8 \%)$, prurigo $(80 ; 1.4 \%)$, genodermatoses $(61 ; 1.1 \%)$, mucocutaneous candidiasis $(40 ; 0.7 \%)$, drug eruptions $(40 ; 0.7 \%)$ and other diseases $(607 ; 11 \%)$. The test results were recorded regardless of age, gender or ethnic group. The association of PS and BMG, family history and heritability of all first-degree members were studied. The project was approved by the ethics and research committee and an informed consent form was signed by each subject. In the statistical analysis, categorical variables are reported as proportions and numeric variables as mean, standard deviation, minimum, and maximum values. The association of PS and BMG was studied comparing to the control group, using the Chi-square and Woolf's tests. A $p$ value $<0.05$ was considered statistically significant. For heritability, the Falconer's test was used.

\section{RESULTS}

The prevalence of PS $(n=129)$ among the studied population was of $2.1 \%$ and BMG $(n=420)$ was $7.0 \%$. The PS group included $66(51 \%)$ men and $120(93 \%)$ Caucasians with an average age of 34.4 years, ranging from 2 to 80 years old. The BMG group included 216 (54\%) women and 345 (86\%) Caucasians with an average age of 30.3 years, ranging from 1 to 90 years old. The CG group included $3,119(57 \%)$ women and 4,799 (88\%) Caucasians at an average age of 28.5 years, ranging from 1 to 92 years old (Table 1 ). The incidence of BMG in the PS group was $16.3 \%$, statistically higher than the control group $(6.8 \%)$, as shown in table 2. Regarding family history, the PS group presented 38\% for this disease and 9.3\% for BMG. Thus, the BMG group showed positive family history for this condition in $27.3 \%$ and for PS in $2.7 \%$. The estimation of heritability was $38.8 \%$ for PS and $36.6 \%$ for BMG, both with medium heritability, taken from table 3 .

\section{DISCUSSION}

The incidence of PS was $2.15 \%$, presenting a similar frequency reported in studies performed in other countries. ${ }^{1,19}$ This data represents the first epidemiologic study of the prevalence of PS in a Brazilian population, and this is the first study on the prevalence of BMG in a Brazilian population of dermatology patients. The frequency of BMG among dermatological conditions was $7.0 \%$ and is equivalent to the observed in literature, which varies from 1.14 to $6.8 \% .{ }^{20,21}$ However, the analysis of this association was

\begin{tabular}{|c|c|c|c|}
\hline Data & PS $(n=129)$ & BMG $(n=420)$ & $C G(N=5.451)$ \\
\hline GENDER & - & - & - \\
\hline Women (\%) & $66(51 \%)$ & $216(54 \%)$ & 3.119 (57\%) \\
\hline Men (\%) & $63(49 \%)$ & $204(46 \%)$ & $2.332(43 \%)$ \\
\hline ETHNICITY & - & - & - \\
\hline White (\%) & $120(93 \%)$ & $345(86 \%)$ & $4.799(88 \%)$ \\
\hline Non-white (\%) & $9(7 \%)$ & 75 (14\%) & $652(12 \%)$ \\
\hline $\begin{array}{l}\text { AGE (mean } \pm \\
\text { SD, years) }\end{array}$ & $34 \pm 14$ & $30 \pm 19$ & $28 \pm 17$ \\
\hline
\end{tabular}

$\mathrm{SD}=$ Standard Deviation 
TABLE 2: Sample distribution according to the presence of benign migratory glossitis (BMG) in psoriasis (PS) and control groups (CG)

\begin{tabular}{lcc} 
BMG & PS & CG \\
\hline & $\mathbf{N}(\%)$ & $\mathbf{N}(\%)$ \\
YES & $21(16.3)$ & $399(6.8)$ \\
NO & $108(83.7)$ & $5.472(93.2)$ \\
TOTAL & $129(100)$ & $5.871(100)$ \\
\hline
\end{tabular}

Risk limit $(\mathrm{Y})$ Mean $=-0.9986$; Relative Risk $(\mathrm{X})=0.37$; Reliability limit $(95 \%)$ : -1.467 standard deviation $(\mathrm{sd})=0.2394 ; \mathrm{X}^{2}(1)=17.399$

limited since no other BMG prevalence data in dermatology patients are available. The PS group presented an increased frequency of BMG (16.3\%), statistically significant compared to the control group (Table 1). This frequency was higher than the ones found in other publications of oral evaluation in PS patients. ${ }^{6,22}$ The increased frequency of BMG in patients with PS allowed several authors to imply that PS and BMG are associated conditions, and that was confirmed in the present research. Picciani et al. (2016) showed that BMG is frequent in psoriatic patients, presenting histopathological, immunohistochemical and genetic similarities with this disease. $^{23}$ However, some investigators do not agree, and the difficulty in accepting the diagnosis of BMG as oral psoriasis resides in the fact that some nonpsoriatic patients present BMG. ${ }^{9,10}$ It is perfectly understandable that a subset of psoriasis patients might have exclusive oral lesions, a situation common to other diseases such mucosal lichen planus. ${ }^{24}$ The presented data showed that the PS group had a family history for this disease in $38 \%$, similar to what is found in the literature, ranging from $36 \%$ to $91 \% .{ }^{25}$ For BMG, positive family history was found in $9.3 \%$. In the BMG group, $27.3 \%$ had positive family history for this condition and and $2.7 \%$ had family history of psoriasis (Table 3). Similar percentage was reported by Eidelman et al. (1976). These

\begin{tabular}{|c|c|c|c|c|c|c|c|}
\hline Disease & Heritability & $\mathbf{A}$ & $\mathbf{N}$ & $q$ & $\mathbf{P}$ & $\mathbf{x}$ & $\mathbf{a}$ \\
\hline PS & $\begin{array}{l}\text { First-degree } \\
\text { relatives }\end{array}$ & 33 & 6.000 & 0.005 & 0.995 & 2.576 & 2.892 \\
\hline PS & Propositi & 129 & 6.000 & 0.02 & 0.98 & 2.054 & 2.421 \\
\hline BMG & $\begin{array}{l}\text { First-degree } \\
\text { relatives }\end{array}$ & 72 & 6.000 & 0.012 & 0.98 & 2.257 & 2.603 \\
\hline BMG & Propositi & 399 & 6.000 & 0.07 & 0.93 & 1.476 & 1.918 \\
\hline
\end{tabular}

Propositi: disease individuals; A: observed number of affected individuals in the sample; $\mathrm{N}$ : total number of individuals in the sample; $\mathrm{q}$ : incidence $=\mathrm{A} / \mathrm{N}$; $\mathrm{p}: 1-\mathrm{q}$; " $\mathrm{x}$ " and " $\mathrm{a}$ " are parameters of the standardized normal distribution, corresponding to incidence $q$, and whose values were taken from the table in Appendix A from Falconer (1965). ${ }^{17}$

authors reported that collecting family history was an arduous task, often requiring more than one visit for the patient to bring appropriate data from the family, and where necessary, the patient's relatives were contacted. ${ }^{26}$ A lack of thorough assessment may explain the lower rate of heritability found in the literature. Such family history from one condition to another had never been reported before. The estimation of heritability for the PS group indicated a medium heritability revealing that in this population, $38.8 \%$ of the determinant of phenotypic variability of PS is of genetic origin, and $61.2 \%$ due to environmental factors. In the BMG group, the estimation of heritability also indicated a medium heritability, revealing that $36.6 \%$ of the determinant of phenotypic variability of BMG is of genetic origin, and $63.4 \%$ due to environmental factors. Our study has some limitations because the sample was selected from only one region in Brazil. However, to minimize this limitation, we evaluated 6000 patients of different ethnicities.

\section{CONCLUSION}

This is the first publication on PS and BMG that quantifies the percentage of the genetic components in these two diseases and shows the importance of the environmental factors in their manifestation. This information may be very important for professionals for they may guide their practice with each patient. $\square$ 


\section{REFERENCES}

1. Patel M, Cohen JM, Wright NA, Merola JF, Qureshi AA, Vleugels RA. Epidemiology of concomitant psoriasis and hidradenitis suppurativa (HS): Experience of a tertiary medical center. J Am Acad Dermatol. 2015;73:701-2.

2. Ikäheimo I, Silvennoinen-Kassinen S, Karvonen J, Tiilikainen A. The frequency of QAP2.1 is increased in psoriasis vulgaris patients but no unusual linkage between QAP/DQA1 or QBP/DQB1. Arch Dermatol Res. 1997;289:373-7.

3. Ladizinski B, Lee KC, Wilmer E, Alavi A, Mistry N, Sibbald RG. A review of the clinical variants and the management of psoriasis. Adv Skin Wound Care. 2013;26:271-84.

4. Peters BP, Weissman FG, Gill MA. Pathophysiology and treatment of psoriasis. Am J Health Syst Pharm. 2000;57:645-59.

5. Gonzaga HF, Torres EA, Alchorne MM, Gerbase-Delima M. Both psoriasis and benign migratory glossitis are associated with HLA-CW6. Br J Dermatol. 1996;135:368-70.

6. Picciani BL, Silva-Junior G0, Michalski-Santos B, Avelleira JC, Azulay DR, Pires FR, et al. Prevalence of oral manifestations in 203 patients with psoriasis. J Eur Acad Dermatol Venereol. 2011;25:1481-3.

7. Picciani BL, Carneiro S, Sampaio AL, Santos BM, Santos VC, Gonzaga HF, et al. A possible relationship of human leucocyte antigens with psoriasis vulgaris and geographic tongue. J Eur Acad Dermatol Venereol. 2015;29:865-74.

8. Samit AM, Greene GW Jr. Atypical benign migratory glossitis. Report of a case with histologic and electron microscopic evaluations. Oral Surg Oral Med Oral Pathol. 1976;42:780-91.

9. Jainkittivong A, Langlais RP. Geographic tongue: clinical characteristics of 188 cases. J Contemp Dent Pract. 2005;6:123-35.

10. Tomb R, Hajj H, Nehme E. Oral lesions in psoriasis. Ann Dermatol Venereol. 2010;137:695-702.

11. Femiano F. Geographic tongue (migrant glossitis) and psoriasis. Minerva Stomatol. 2001:50:213-7.

12. Picciani B, Silva-Junior G, Carneiro S, Sampaio AL, Goldemberg DC, Oliveira J, et al. Geographic stomatitis: an oral manifestation of psoriasis? J Dermatol Case Rep. 2012;6:113-6.

13. Chandran V. The genetics of psoriasis and psoriatic arthritis. Clin Rev Allergy Immunol. 2013;44:149-56.
14. Chen H, Poon A, Yeung C, Helms C, Pons J, Bowcock AM, et al. A genetic risk score combining ten psoriasis risk loci improves disease prediction. PLoS One. 2011;6:e19454

15. Matthews D, Fry L, Powles A, Weber J, McCarthy M, Fisher E, et al. Evidence that a locus for familial psoriasis maps to chromosome 4q. Nat Genet. 1996;14:231-3.

16. Elder JT, Nair RP, Guo SW, Henseler T, Christophers E, Voorhees JJ. The genetics of psoriasis. Arch Dermatol. 1994;130:216-24.

17. Pass B, Brown RS, Childers EL. Geographic tongue: literature review and case reports. Dent Today. 2005;24:54, 56-7.

18. Falconer DS. The inheritance of liability to diseases with variable age of onset, with particular reference to diabetes mellitus. Ann Hum Genet. 1967;31:1-20.

19. Elder JT, Bruce AT, Gudjonsson JE, Johnston A, Stuart PE, Tejasvi T, et al. Molecular dissection of psoriasis: integrating genetics and biology. $J$ Invest Dermatol. 2010;130:1213-26.

20. Gonzaga HFS, Costa CAS, Oliveira MRB, Nordi PP, Pires RH, Milori AS, et al. Prevalence of geographic and fissure tongue in 808 Araraquara schoolchildren. Rev Odontol UNESP. 1994;23:339-46.

21. Koay CL, Lim JA, Siar CH. The prevalence of tongue lesions in Malaysian dental outpatients from the Klang Valley area. Oral Dis. 2011;17:210-6.

22. Hernández-Pérez F, Jaimes-Aveldañez A, Urquizo-Ruvalcaba Mde L, Díaz-Barcelot $M$, Irigoyen-Camacho ME, Vega-Memije ME, et al. Prevalence of oral lesions in patients with psoriasis. Med Oral Patol Oral Cir Bucal. 2008;13:E703-8.

23. Picciani BL, Domingos TA, Teixeira-Souza T, Santos Vde C, Gonzaga HF, CardosoOliveira J, et al. Geographic tongue and psoriasis: clinical, histopathological, immunohistochemical and genetic correlation - a literature review. An Bras Dermatol. 2016;91:410-21.

24. Bruce AJ, Rogers RS 3rd. Oral psoriasis. Dermatol Clin. 2003:21:99-104.

25. Elder JT, Nair RP, Henseler T, Jenisch S, Stuart P, Chia N, et al. The genetics of psoriasis 2001: the odyssey continues. Arch Dermatol. 2001;137:1447-54.

26. Eidelman E, Chosack A, Cohen T. Scrotal tongue and geographic tongue: polygenic and associated traits. Oral Surg Oral Med Oral Pathol. 1976;42:591-6.

How to cite this article: Jorge MA, Gonzaga HFS, Tomimori J, Picciani BLS, Barbosa CA. Prevalence and heritability of psoriasis and benign migratory glossitis in one Brazilian population. An Bras Dermatol. 2017;92(6): 816-9. 